\title{
Propolis supplementation improves glycemic and antioxidant status in patients with type 2 diabetes: A randomized, double-blind, placebo-controlled study
}

By:Afsharpour, F (Afsharpour, Fatemeh) ${ }^{[1,3]}$; Javadi, M (Javadi, Maryam) ${ }^{[1,2]}$; Hashemipour, S (Hashemipour, Sima $)^{[3]}$; Koushan, Y (Koushan, Yaghob) ${ }^{[4]}$; Haghighian, HK (Haghighian, Hossein Khadem $)^{[1,3]}$

\section{COMPLEMENTARY THERAPIES IN MEDICINE}

Volume: 43, Pages: 283-288,DOI: 10.1016/j.ctim.2019.03.001,Published: APR 2019

Document Type:Article

View Journal Impact

\section{Abstract}

Objectives: The prevalence of type 2 diabetes has risen dramatically in recent years. There are many different safe therapies used for diabetes and also number of natural supplements that can be used to manage diabetes. We assessed the effect of oral propolis supplementation on blood glucose, insulin resistance and antioxidant status in type 2 diabetes.

Methods: We conducted a randomized, double-blinded, placebo-controlled trial for 8-week. Sixty two patients with type 2 diabetes (30-55 years of age) were randomly assigned in two group, propolis $(n=31)$ and placebo $(n=31)$. Patients were given doses of $500 \mathrm{mg}$, three times a day $(1500 \mathrm{mg})$, of propolis or placebo three time a day. The fasting blood sugar (FBS), two-hour postprandial glucose (2-hp), insulin, insulin resistance (IR), hemoglobin A(1)c $(\mathrm{HbA}(1) \mathrm{c})$, total antioxidant capacity (TAC) and activity of glutathione peroxidase (GPx) and superoxide dismutase (SOD) were measured at the beginning and end of the study. Statistical analysis was performed using SPSS software.

Results: After two month, FBS, 2-hp, insulin, IR, $\mathrm{HbA}(1) \mathrm{c}$ was significantly decreased in patients treated with propolis compared with placebo group $(p<0.05)$. Additionally intake of propolis significantly increased the blood levels of TAC and activity of GPx and SOD ( $p<0.05)$.

Conclusion: Propolis treatment can be helpful as a diet supplement in patients with type 2 diabetes through improvement in glycemic status, reduction in insulin resistance and amelioration in antioxidant status. This supplement without side effects can increase the effectiveness of prescribing drugs in diabetes.

\section{Keywords}

Author Keywords:Propolis; Glycemic status; Insulin resistance; Antioxidant; Type 2 diabetes KeyWords Plus:INSULIN-RESISTANCE; OXIDATIVE STRESS; RATS; MELLITUS; DISEASE

\section{Author Information}

Reprint Address: Haghighian, HK (reprint author)

+ Qazvin Univ Med Sci, Fac Hlth, Dept Nutr, Qazvin, Iran.

\section{Addresses:}

+ [1 ] Qazvin Univ Med Sci, Sch Hlth, Dept Nutr, Qazvin, Iran

+ [2] Qazvin Univ Med Sci, Children Growth Res Ctr, Qazvin, Iran

+ [ 3 ] Qazvin Univ Med Sci, Metab Dis Res Ctr, Qazvin, Iran

+ [ 4 ] Islamic Azad Univ Tabriz, Med Plant Res Ctr, Tradit Med, Tabriz, Iran

E-mail Addresses:khademnut@yahoo.com 
